\title{
Influence of the Type of Phase Change Materials Microcapsules on the Properties of Lime-Gypsum Thermal Mortars**
}

\author{
By Sandra Cunha, José B. Aguiar, ${ }^{*}$ Victor M. Ferreira and A. Tadeu
}

In a society with a high growth rate and increased standards of comfort arises the need to minimize the currently high energy consumption by taking advantage of renewable energy sources. The mortars with incorporation of phase change materials (PCM) have the ability to regulate the temperature inside buildings, contributing to the thermal comfort and reduction of the use of heating and cooling equipment, using only the energy supplied by the sun. However, the incorporation of PCMs in mortars modifies its characteristics. The main purpose of this study was the production and characterization of mortars with incorporation of two different PCMs. Specific properties of two PCMs, such as particle size, shape, and enthalpy, were determined, as well as the properties of the fresh and hardened state of the mortars. The proportion of PCM was 0,10,20, and 30\% of the total mass of the solid particles. In order to minimize some problems associated with shrinkage and consequent cracking of the mortars, the incorporation of polyamide fibers and superplasticizer was tested. It was possible to observe that the incorporation of PCMs in mortars caused differences in properties such as compressive strength, flexural strength, and shrinkage. Even though the incorporation of PCM microcapsules resulted in an increase in the shrinkage, it was possible observe a significant improvement in mechanical properties.

\section{Introduction}

Every year, about $5 \times 10^{24} \mathrm{~J}$ of energy is powered by the sun and reaches the entire land surface. This amount is about 10000 times higher than the actual energy consumption per year worldwide. Thus, the need to find a way to take advantage of this natural energy source is pressing. ${ }^{[1]}$ Presently, the concerns related to the energy consumption of buildings are greater than ever, resulting in the need to incorporate materials in the construction products that can improve the energetic efficiency of buildings.

[*] Prof. J. B. Aguiar, S. Cunha

Department of Civil Engineering, University of Minho, Campus de Azurém, 4800-058, Guimarães, Portugal

E-mail: aguiar@civil.uminho.pt

Prof. V. M. Ferreira

Department of Civil Engineering, University of Aveiro, Campus Universitário de Santiago, 3810-193, Aveiro, Portugal A. Tadeu

Department of Civil Engineering, University of Coimbra, Rua Luís Reis Santos - Pólo II, 3030-788, Coimbra, Portugal

[**] The authors wish to express their thanks to the Portuguese Foundation for Science and Technology, for funding the project PTDC/ECM/102154/2008, Contribution of Thermal Active Mortars for Building Energy Efficiency.
The high growth rate of urban areas and the increase of parameters caused an increase in energy consumption, making it one of the major concerns of modern society. This problem is related with the excessive use of energy from nonrenewable sources, which cause serious environmental impacts.

The largest part of the energy consumption in residential sector is associated with heating and cooling. Therefore, it becomes imperative to obtain a constructive solution that minimizes these consumptions, improving the level of comfort inside buildings without damaging the environment. Furthermore, it is important to consider constructive solutions with renewable energy resources, providing an improvement in the quality of the buildings, especially in the comfort level of the occupants, without problems to the environment.

The incorporation of phase change materials (PCM) in mortars for the interior appears as a possible solution in an attempt to solve, or at least minimize, the massive energetic consumption related with buildings. The use of this material allows the regulation of temperature inside buildings through latent heat thermal energy storage, using only solar energy as a resource, or at least reducing the need to use heating and cooling equipment.

Latent heat thermal energy storage, through the incorporation of PCM, presents advantages such as narrow the gap between the peak and off-peak loads, leveling the electricity 
demand, decreasing the load on the network and eventual supply failure; reduce operation costs by shifting the electrical consumption from peak periods to off-peak periods; contribute to the interior thermal comfort in buildings, by using and storing solar. ${ }^{[2,3]}$ The benefit to the interior thermal comfort inside buildings is materialized by the phase change occurring in the PCM.

Between all PCMs possible applications in buildings, the most interesting is its incorporation in construction materials altering their materials thermal properties. The PCM may be used for thermal storage of passive solar heating being integrated in the floor, walls or ceilings, as well as being an integrating part of the most complex energetic system, such as heat pumps and solar panels. ${ }^{[4]}$

The low thickness achieved with the use of PCMs combined with the utilization of flexible construction solution makes possible to obtain a greater adaptability of the buildings, moving the traditional construction for a more sustainable construction. The incorporation of PCMs in interior mortars, with the aim to reduce energetic consumption, allows us to delineate new ways to obtain a construction with a higher value of sustainability. Therefore, it is important that the construction industry is innovative and accepts new solutions for solving problems with several years.

The main objective of this study was the production and study of a mixed lime-gypsum mortar with incorporation of PCMs microcapsules available in the market. Two PCMs were used in the production of the mortars in order to analyze their influence in properties like workability, shrinkage, compressive, and flexural strengths.

\section{Phase Change Material}

It is known that all materials interact with the environment, however most of them lack the capability to alter its own properties according to the environment characteristics in which they are applied.

From all the existing materials, water is ease to understanding and to assimilate the phase change concept. Water can be found in the solid, liquid, and gaseous states. The transition process from the solid state to the liquid state assumes the designation of fusion. The inverse process can be designated as solidification. The two processes occur at about $0{ }^{\circ} \mathrm{C}$. On the other hand, the transition from the liquid state to gaseous state is referred as vaporization. The inverse process is condensation. The two processes occur at about $100^{\circ} \mathrm{C}$. Each state change has associated an amount of energy denominated enthalpy.

PCMs possess the capability to alter its own state as function of the environmental temperature. ${ }^{[4]}$ In other words, when the surrounding environmental temperature of PCM increases until the materials fusion point, it suffers a change from a solid state to a liquid state, absorbing and storing the heat energy from the environment. On the other hand when the temperature decreases until the PCM solidification point, the material alters from the liquid state to solid state, releasing the previously stored energy to the environment. This application could be made in coating mortars of buildings, with advantage in the passive regulation of internal temperature with increase of thermal inertia. ${ }^{[5]}$

The PCMs with phase transition from solid to liquid are preferred for the thermal energy storage, because the associated volume variation is lower than the associated to the transition from liquid to gaseous or from gaseous to solid. ${ }^{[6,7]}$

The PCM must be encapsulated, for its correct use, otherwise during the liquid phase there is a possibility that it moves from the original area of application. There are two main forms of encapsulation, macroencapsulation, and microencapsulation. The macroencapsulation is based in the introduction of PCM into tubes, panels, or other large containers. It is usually done in containers with more than $1 \mathrm{~cm}$ in diameter and presents a better compatibility with the material, improving the handling in construction. ${ }^{[8]}$ The microencapsulation of PCM consists on covering the material particles, with a material, usually a polymer, commonly known capsule, with dimensions between 1 and $60 \mu \mathrm{m}$. The polymer used could be polymethylmethacrylate, polyuria or polyurethane and should respond at some demands of operation, as high heat transfer. The microcapsules can be spherical or asymmetric and with variable shape. The advantage of this encapsulation process is the improvement of heat transfer, through its large surface area. ${ }^{[8,9]}$

In 1983, emerged the first classification of substances used for thermal storage. These are classified as organic, inorganic, and eutectic mixtures. Organic materials can be non-paraffinic or paraffinic. Usually, they have congruent phase changes without degradation. The inorganic materials are classified as hydrated salts and metals. The eutectic mixtures result from the combination of two or more compounds of organic and/or inorganic nature. By this way, it is possible to correspond to the need of more suitable transition temperatures for the demands. ${ }^{[8,10]}$

Not all existing PCM can be used for thermal storage. An ideal PCM must present certain thermophysic, kinetic, chemical, and economic properties. Thermophysically, the transition temperature for the selected PCM must be within the desired range in order to guarantee both the storage and release of thermal energy. A high transition heat by volume unit is also required, so as to maximize the stored energy while minimizing the PCM usage, as well as a high sensitive heat (represented by its calorific capability), which allows for an increase in its energy storing capability. Furthermore, high thermal conductivity characteristics in both solid and liquid states promote heat transfer with a reduced variation in volume during phase transition, reducing contention issues. From the kinetic point of view, a high growth velocity of the crystals can prevent sub cooling of the PCM liquid phase, enhancing its response to the surrounding demands. Thirdly, regarding the chemical properties, the chosen PCM should not be susceptible to degradation following a high number of cycles, while it must also be non-corrosive to construction 
materials, as well as non-flammable, non-toxic, and nonexplosive, in order to attend to environmental and security concerns. Finally, bearing in mind economic characteristics, availability and low acquisition cost are the main factors preceding the establishment of PCM as a competitive solution in comparison to conventional constructive and thermal storing systems. ${ }^{[8]}$

\section{Contribution to Sustainable Construction}

Sustainable development is closely connected to three dimensions: economic, social, and environmental. It is important to have a balance and harmony between them. The creation of a strong connection between the construction industry and the pillars of sustainable development is particularly important and early started to merit the attention of stakeholders in the construction sector.

The incorporation of PCM microcapsules in mortars brings social, economic, and environmental benefits, demonstrating a significant contribution to a construction with a higher value of sustainability. The social benefits derive from the thermal comfort increase inside buildings, given that nowadays this is an important requirement and frequently demanded by buyers and potential sellers as an important decision parameter. The increase of thermal comfort is achieved by the thermal capacity of the PCM, allowing store and release of energy, keeping the interior temperature sensibly constant, or at least with less variation. The environmental aspect concerns the fossil fuels depletion, given that this technology aims at maintaining constant temperatures inside the building, consequently leading to a decrease on air conditioning equipment usage. The economic benefit is related to the technology adequacy and implementation costs. These should be supported and easily amortized by the user. It may also be noted that the economic benefits of reduced energy consumption and lag times for lower demand, are evident and can be achieved with the use of PCM.

\section{Application of Phase Change Materials in Construction}

Currently, the thermal energy storage has been aroused more interest. It is known that the use of PCM has a great influence in areas where winter and summer are more rigorous. ${ }^{[4,11-13]}$

The selection of the PCM transition temperature adequated to the atmospheric temperature is extremely important for the functionality of the solution. The adequacy of several PCM for incorporation in gypsum plasterboard was studied by Khudhair and Farid ${ }^{[11]}$ Although the employed materials presented a great ability for energy storing capability, their transition temperature did not achieve the comfort band. This study shows the suitability of various PCM for incorporation into gypsum boards. However, despite having large thermal storage capacity, the used PCM was not placed in operation, because the transition temperature did not coincide with the range of comfort temperature.
PCM can be used in solutions for walls, floors, and ceilings. Presently, also exist some commercial solutions. The application of PCM in the walls of buildings is the preferential solution for exploring the potential of these materials. The incorporation of PCMs in gypsum plasterboard has been the subject of several studies performed due to its low cost and various possibilities of application. ${ }^{[14-17]}$ Darkwa et al., investigated the behavior of two solutions with incorporation of PCM in gypsum plasterboard. In one side the plasterboard used had $12 \mathrm{~mm}$ of thickness, all impregnated with PCM in order to compare with another situation in which they applied simple plasterboards with $10 \mathrm{~mm}$ of thickness, covered by PCM laminate with $2 \mathrm{~mm}$. The amount of PCM incorporated in both cases was the same. The results showed that the use of PCM laminate is more efficient since it contributed to an increase in the minimum temperature. ${ }^{[16]}$

However, other solutions had also been developed like alveolar PVC panels with PCM macroencapsulated, blocks and bricks. ${ }^{[8,18]}$ Cabeza et al., constructed and monitored the behavior of concrete test cells, with and without addition of $5 \%$ of PCM microcapsules. The incorporation of PCM was made in the concrete used on the roof and south and west walls. During the summer and without ventilation a decrease in maximum temperature and a time lag of about $2 \mathrm{~h}$ were recorded. ${ }^{[8]}$

The floors are probably one of the most important locals for heating and cooling a building. There are several authors who had investigated constructive solutions with incorporation of PCMs, with applications in floors. These solutions are varied, such as electric heating under floor systems incorporating polyethylene plates impregnated with PCM, incorporation of PCM in concrete slab and the application of two types of PCM with different transition temperatures. ${ }^{[10,19-21]}$

The use of constructive solutions on ceilings ranges from the gypsum panels to steel panels with circulation of PCM in capillary networks. ${ }^{[22,23]}$

\section{Materials, Compositions and Fabrication}

\subsection{Materials}

The selection of the materials took in account previous works. Special attention was given to the selection of the binder. The use of cement and gypsum reveals decrease of mechanical strengths with the incorporation of PCM microcapsules. In order to solve this problem the study was made with aerial lime and gypsum as binders. ${ }^{[2,3]}$ The use of these two binders together reveals an interesting behavior and solved the problems founded with other binders.

In this research, aerial lime and gypsum mortars had been developed. Polyamide fibers and superplasticizers were incorporated to solve problems related with the specific properties of the mortars.

In this investigation, two different types of PCM microcapsules, designated as A and B, were used. Both samples were used in powder form that means completely dry, although there is also the possibility of obtaining the same 
material in emulsion. In this study, we decided to use the dry PCM in order to facilitate their incorporation in pre-mixed mortars.

The PCM microcapsules tests were performed in order to compare the PCM provided by two different producers. The microcapsules A are constituted by a wall in polymethylmethacrylate and a core in paraffin, with transition temperature of about $22.5^{\circ} \mathrm{C}$ and enthalpy of $110 \mathrm{~kJ} \mathrm{~kg}^{-1}$. The microcapsules of PCM A exhibit a transition temperature of $25^{\circ} \mathrm{C}$ in the heating cycle and $20^{\circ} \mathrm{C}$ in the cooling cycle. The microcapsules $\mathrm{B}$ are composed of a wall in melamine-formaldehyde and a core in paraffin, with temperature transition of about $22.5^{\circ} \mathrm{C}$ and enthalpy of $147.9 \mathrm{~kJ} \mathrm{~kg}^{-1}$. These exhibit a transition temperature of $24^{\circ} \mathrm{C}$ in the heating cycle and $21^{\circ} \mathrm{C}$ in the cooling cycle.

The tests conducted using the high resolution scanning electron microscope indicate that the polymer present in the microcapsules A is rougher (Figure 1) compared to the polymer used in the microcapsules B (Figure 2) that presents a more regular texture.

With the purpose of obtain more information related with the dimensions of PCM microcapsules granulometry tests were performed, using a laser particle size analyzer. It was possible to observe that the microcapsules $\mathrm{A}$ are agglomerated, having a greater dimension when observed under the electron microscope. However, the agitation that the sample suffer during the laser particle size analyze, allows the dispersion of agglomerated microcapsules. In this way, it was possible to conclude that the microcapsules $\mathrm{A}$ have a particle size distribution between 5.8 and $219 \mu \mathrm{m}$ and an average particle size of $37.24 \mu \mathrm{m}$. The microcapsules B present a particle size distribution between 5.8 and $339 \mu \mathrm{m}$ and an average particle size of $43.91 \mu \mathrm{m}$ (Figure 3).

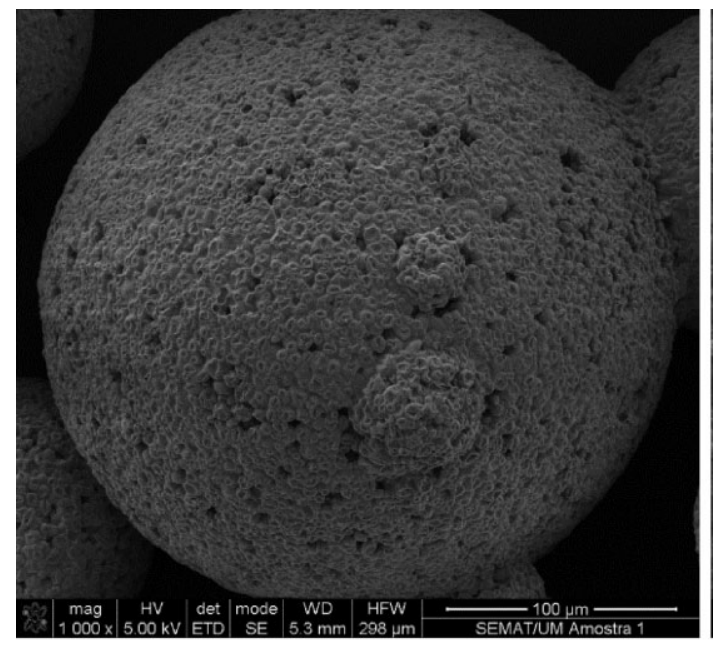

a)

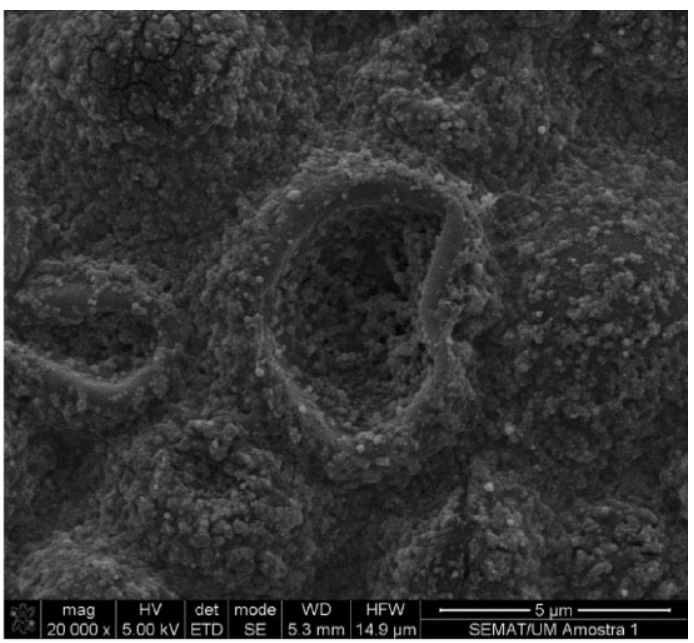

b)

Fig. 1. Microscope observation of polymer surface of the microcapsules A: (a) enlargement of $1000 \times$; (b) enlargement of $20000 \times$.

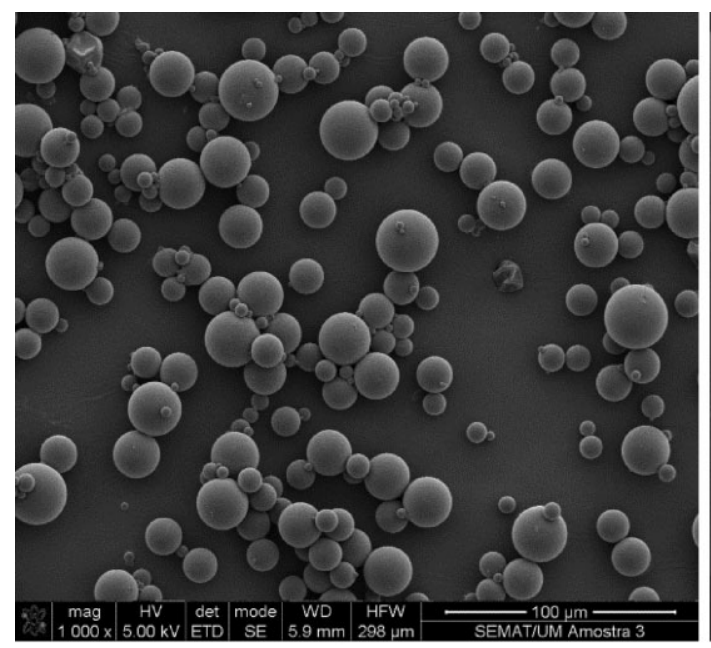

a)

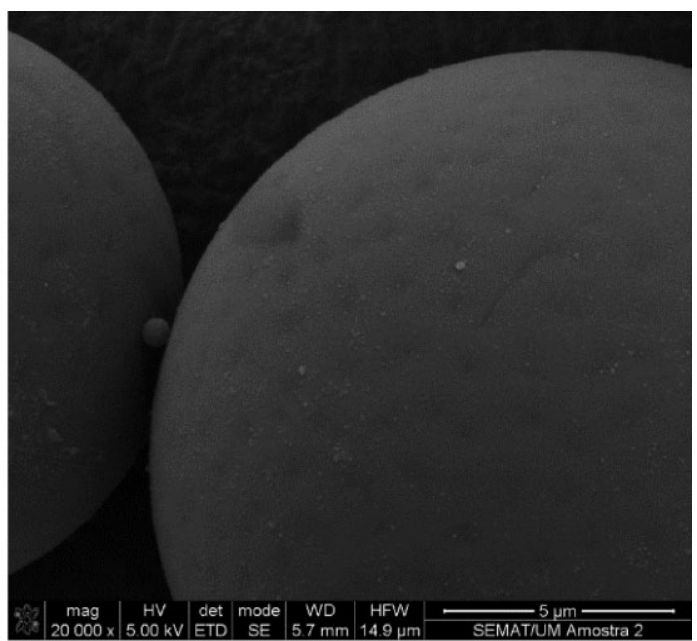

b)

Fig. 2. Microscope observation of polymer surface of the microcapsules B: (a) enlargement of $1000 \times$; (b) enlargement of $20000 \times$. 


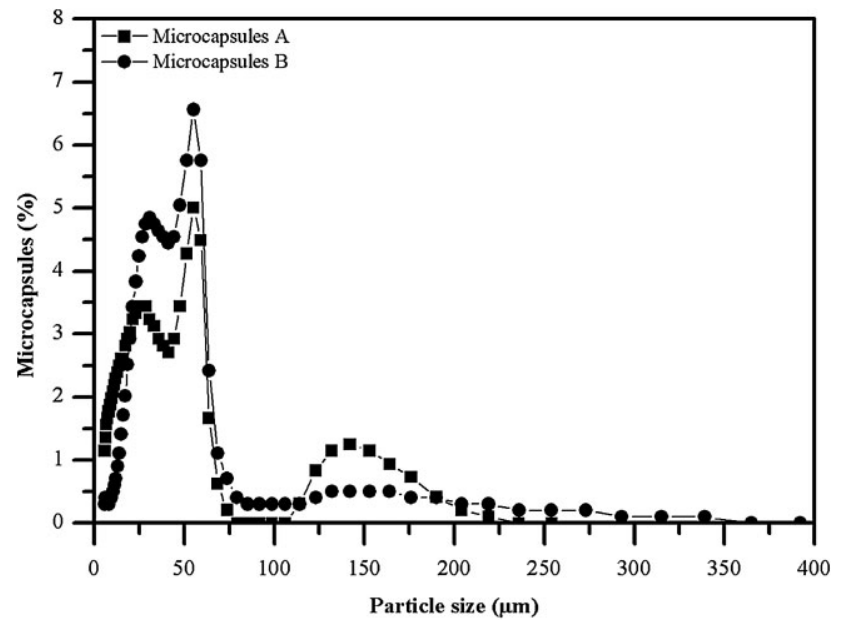

Fig. 3. Particle size distribution of PCM microcapsules.

The superplasticizer used was a polyacrylate, with a density of $1050 \mathrm{~kg} \mathrm{~m}^{-3}$. The sand used has an average particle size of $439.9 \mu \mathrm{m}$ and a density of $2600 \mathrm{~kg} \mathrm{~m}^{-3}$. The lime used in the compositions was a hydrated lime, with a purity of $90 \%$ and density of $2450 \mathrm{~kg} \mathrm{~m}^{-3}$. The gypsum used is a traditional one, with high fineness and density of $2740 \mathrm{~kg} \mathrm{~m}^{-3}$. Finally, the fibers used are synthetic fibers of polyamide, with a length of $6 \mathrm{~mm}$ and a density of $1380 \mathrm{~kg} \mathrm{~m}^{-3}$.

\subsection{Compositions and Fabrication}

In order to develop this study an experimental campaign was considered, with the main goal of characterizing the produced compositions. Sixteen compositions were developed taking account the future application of the mortar developed in the construction industry. These compositions were evaluated from the fresh state up to 28 days. The compositions tested in this study were based on the information available in Patent PCT/PT2009/000072. ${ }^{[24]}$
The PCM content was fixed in $0,10,20$, and $30 \%$ of total mass of solid particles. In order to overcome some of the problems related with the mortar shrinkage and consequent cracking, polyamide fibers and superplasticizer were incorporated.

The studied compositions are presented in Table 1. The study used compositions with different contents of aerial lime, gypsum, and PCM. For each composition without PCM, it was decided for the no inclusion of superplasticizer due to its dispersive effect, which caused a slight segregation of the mortar.

The mixture procedure and specimens preparation was performed in accordance to the standard EN 1015-11. ${ }^{\text {[25] }}$ To evaluate the mechanical properties (compressive and flexural strengths) of all the different compositions, 3 prismatic specimens with $40 \times 40 \times 160 \mathrm{~mm}^{3}$ were prepared. After their preparation all the specimens were stored during 7 days in polyethylene bags and subsequently placed in the laboratory at regular room temperature (about $22^{\circ} \mathrm{C}$ ) during 21 days.

\section{Test Results and Discussion}

\subsection{Workability}

The workability tests were performed with the main goal of verifying the adequacy of application of the developed mortars. The tests were performed based on the flow table method stated by the European standard EN 1015-3. ${ }^{[26]}$ The resulting value within the test was only considered when between 160 and $180 \mathrm{~mm}$.

It was possible to verify changes in the amount of water added to the mortars, according the incorporation of PCM microcapsules, taking into account the quantity and type of material added.

According to Figure 4, it is possible to observe that the incorporation of $20 \%$ of the microcapsules A causes an increase in the amount of water of about $62 \%$. This situation can

Table 1. Composition of mortars (Microcapsules of PCM, superplasticizer, water, and fibers as \% of total mass of solid particles; gypsum, and sand as \% of binders mass).

\begin{tabular}{|c|c|c|c|c|c|c|}
\hline Compositions & Sand & $\begin{array}{c}\text { Microcapsules } \\
\text { of PCM A }\end{array}$ & $\begin{array}{c}\text { Microcapsules } \\
\text { of PCM B }\end{array}$ & Fibers & Gypsum & Superplasticizer \\
\hline L100G0 & 561.4 & 0.0 & 0.0 & 0.0 & 0.0 & 0.0 \\
\hline L90G10 & 561.4 & 0.0 & 0.0 & 0.0 & 10.0 & 0.0 \\
\hline L100G0PCM20-A & 561.4 & 20.0 & 0.0 & 0.1 & 0.0 & 1.0 \\
\hline L100G0PCM20F-A & 561.4 & 20.0 & 0.0 & 0.1 & 10.0 & 1.0 \\
\hline L90G10PCM10F-A & 561.4 & 10.0 & 0.0 & 0.1 & 10.0 & 1.0 \\
\hline L90G10PCM20F-A & 561.4 & 20.0 & 0.0 & 0.1 & 10.0 & 1.0 \\
\hline L90G10PCM30F-A & 561.4 & 30.0 & 0.0 & 0.1 & 10.0 & 1.0 \\
\hline L80G20PCM20F-A & 561.4 & 20.0 & 0.0 & 0.1 & 20.0 & 1.0 \\
\hline L60G40PCM20F-A & 561.4 & 20.0 & 0.0 & 0.1 & 40.0 & 1.0 \\
\hline L100G0PCM20-B & 561.4 & 0.0 & 20.0 & 0.0 & 0.0 & 1.0 \\
\hline L100G0PCM20F-B & 561.4 & 0.0 & 20.0 & 0.1 & 0.0 & 1.0 \\
\hline L90G10PCM10F-B & 561.4 & 0.0 & 10.0 & 0.1 & 10.0 & 1.0 \\
\hline L90G10PCM20F-B & 561.4 & 0.0 & 20.0 & 0.1 & 10.0 & 1.0 \\
\hline L90G10PCM30F-B & 561.4 & 0.0 & 30.0 & 0.1 & 10.0 & 1.0 \\
\hline L80G20PCM20F-B & 561.4 & 0.0 & 20.0 & 0.1 & 20.0 & 1.0 \\
\hline L60G40PCM20F-B & 561.4 & 0.0 & 20.0 & 0.1 & 40.0 & 1.0 \\
\hline
\end{tabular}




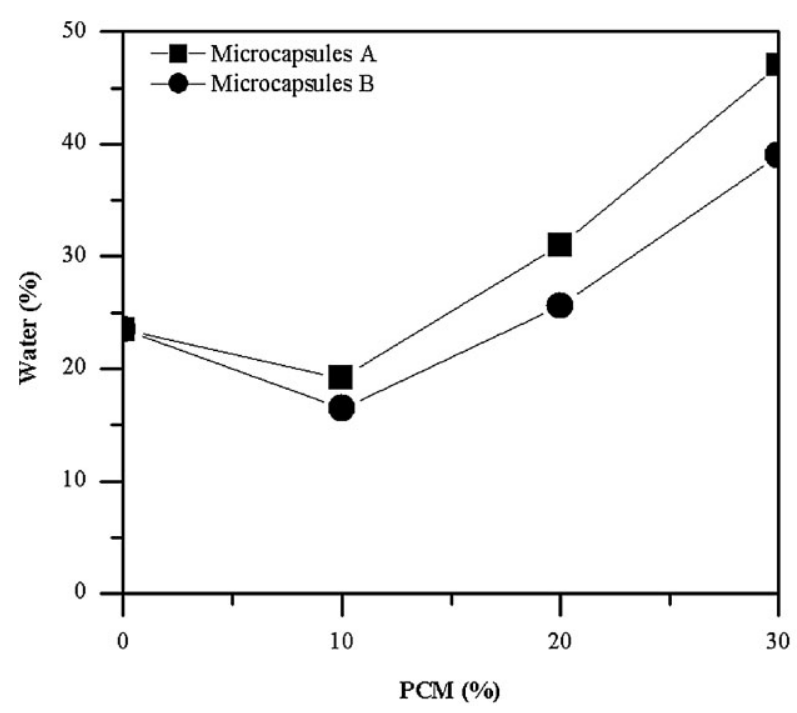

Fig. 4. Water added to the mortar (in $\%$ of total mass of solid particles).

be explained by the reduced particle dimension of the used PCM and by the water absorption of the polymeric wall of the microcapsule. However, the incorporation of microcapsules B also causes an increase in the amount of water, but smaller, this being only about $12 \%$. This behavior can be explained by the use of capsules with a less rough surface and higher particle dimension.

The incorporation of fibers did not cause any change in the amount of water added to the mortar, however there was a slight reduction in the flow diameter obtained for the mortars with incorporation of microcapsules $\mathrm{A}$ and $\mathrm{B}$.

The addition of $10 \%$ gypsum caused a slight increase in the amount of water. Being that, for the same mortar an increase of $20 \%$ of gypsum caused an increase of approximately $4 \%$ in the amount of added water.

\subsection{Shrinkage}

The shrinkage study was performed for only 9 of the 16 compositions studied. Thus, it was possible to observe the influence of the presence of PCM microcapsules in the mortar, as well as the action caused by the introduction of polyamide fibers and gypsum. The introduction of these materials had as main objective the reduction and control of shrinkage.

For evaluating the shrinkage, a device capable of performing the measurement since the time of placing the mortar in the mold until the demolding, at 7 days, was developed. Previously to placing the mortar, the molds of the measuring device were prepared with oil commonly used in formwork, aiming for the elimination of attrition in surfaces. After demolding, it was possible to continue the monitoring of the shrinkage with another device.

The device consists of a base for placing the triple mold with dimensions of $25 \times 25 \times 250 \mathrm{~mm}^{3}$ and six displacement transducers. Two displacement transducers were used for each specimen in order to enable the measurement of shrinkage on both sides further away from the specimen. The transducers

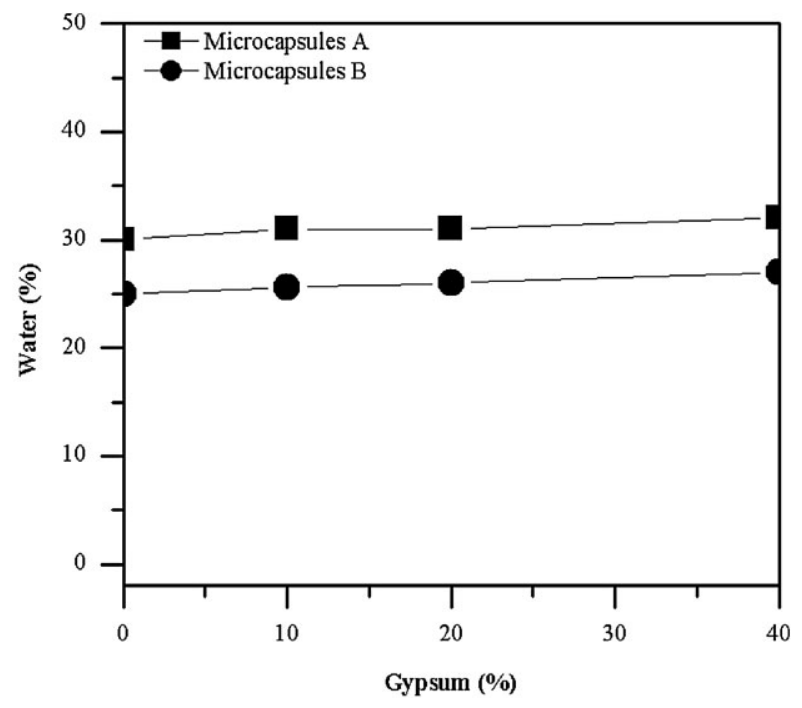

were connected to a data acquisition system, where the values of shrinkage of mortars were registered. It was possible to make an evaluation of shrinkage since the fresh state.

The amount of shrinkage was given by the following equation:

$\varepsilon=\frac{L_{\mathrm{i}}-L_{\mathrm{t}}}{250}$

where

$\varepsilon$-Shrinkage value at time $t$;

$L_{\mathrm{i}}$ - Value of first measurement;

$L_{t}$ - Value of measurements at time $t$.

The results allowed us to verify that there is an increase in the shrinkage with the incorporation of PCM microcapsules in the first $10 \mathrm{~h}$. However, the addition of gypsum and polyamide fibers results in a shrinkage decrease in the first $24 \mathrm{~h}$ of monitoring (Figure 5) in mortars incorporating both types of PCM microcapsules.

The analysis of the results up to 7 days of age (Figure 6) in mortars with incorporation of the microcapsules $\mathrm{A}$, allows the identification of different behaviors. The introduction of $20 \%$ of microcapsules (L100G0PCM20-A), causes an increase in shrinkage of about $300 \%$ compared to the reference mortar (L100G0). The addition of polyamide fibers (L100G0PCM20F-A) causes a decrease in shrinkage to about $50 \%$ compared with the mortar L100G0PCM20-A. With the addition of gypsum (L80G20PCM20F-A and L60G40PCM20F-A), it is possible to observe a decrease in shrinkage. The addition of $40 \%$ gypsum allows a reduction in the shrinkage of about $40 \%$ compared with the mortar L100G0PCM20F-A.

According to Figure 6, the incorporation of $20 \%$ of microcapsules B (L100G0PCM20-B) causes an increase in shrinkage of about $20 \%$ compared to the reference mortar 

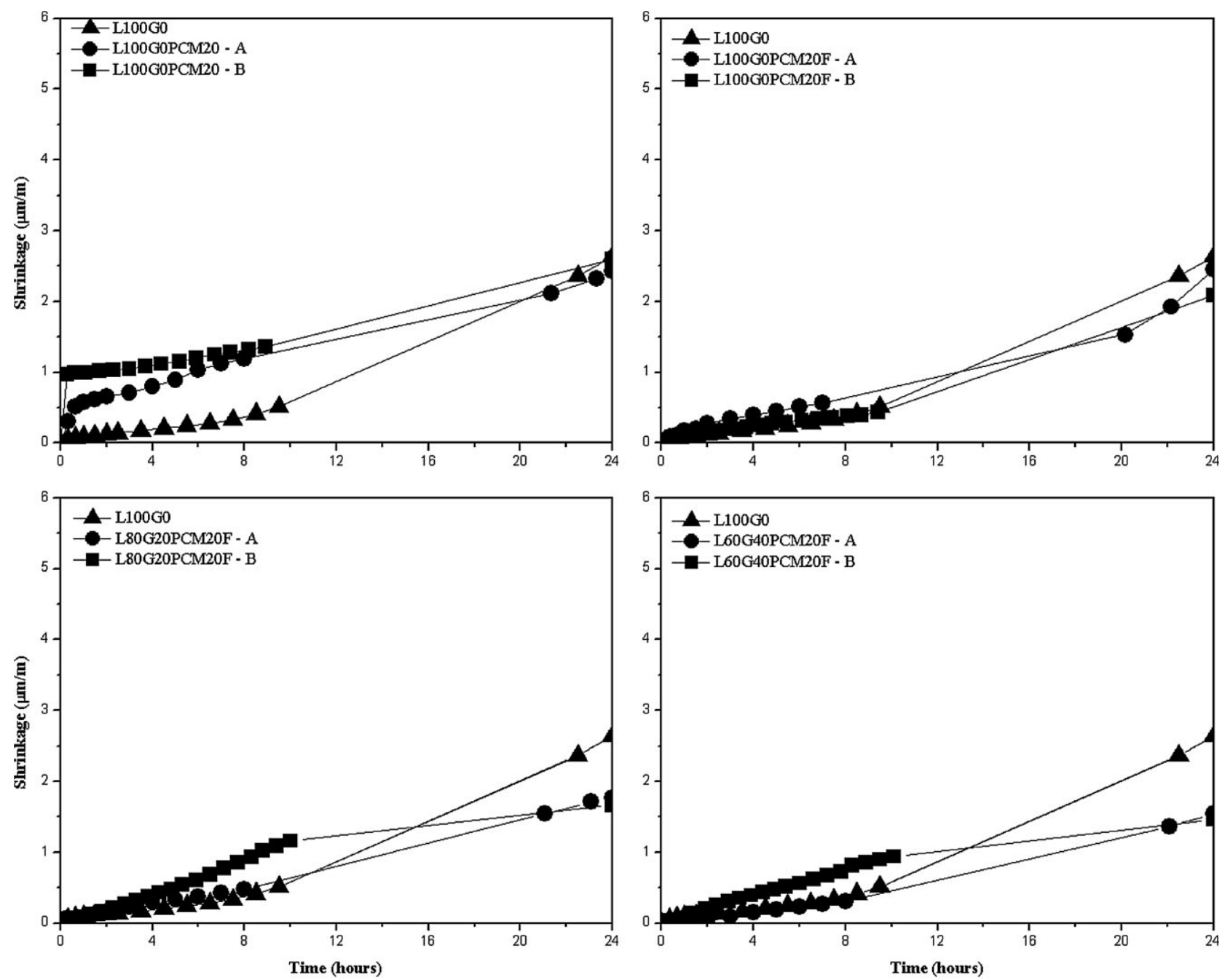

Fig. 5. Shrinkage values since molding until $24 \mathrm{~h}$.
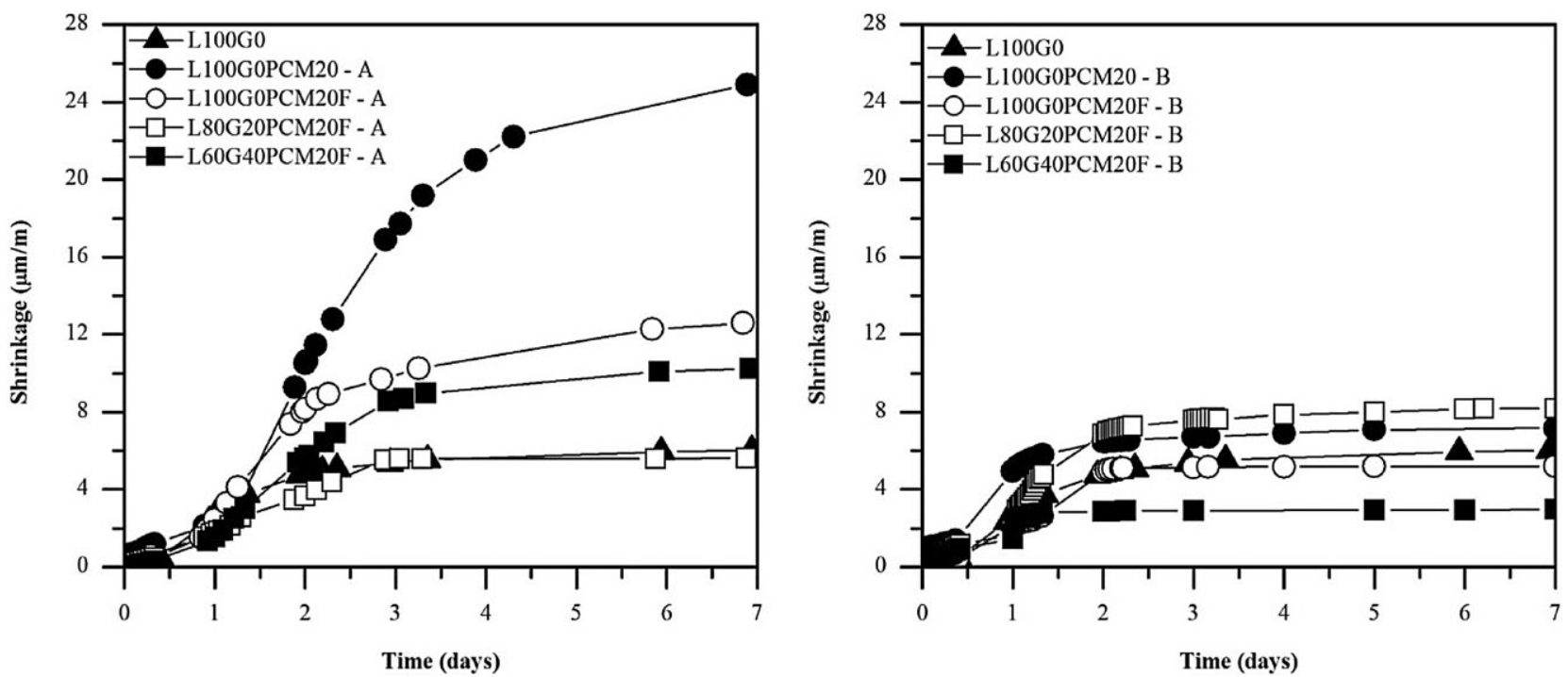

Fig. 6. Shrinkage values since molding until 7 days. 
(L100G0). The incorporation of polyamide fibers (L100G0PCM20F-B) allows for the verification of a decrease of about 30\% compared with the mortar L100G0PCM20-B. Finally, the incorporation of $40 \%$ gypsum (L60G40PCM20F-B) seems to cause a decrease in the value of shrinkage of about $40 \%$ compared with the mortar L100G0PCM20F-B.

The increase in shrinkage with the incorporation of PCM microcapsules is related to a greater amount of water used, while its reduction is caused by the inclusion of fibers, which are related to the prevention of dimension variations inside the mortar. Moreover, the reduction of shrinkage observed with the addition of gypsum, is connected to the expansion, which occurs with its hydration.

The incorporation of $20 \%$ of microcapsules $\mathrm{B}$, compared with the incorporation of $20 \%$ of microcapsules A, causes a decrease in shrinkage of about $70 \%$, which can be explained by the presence of lower water content in the mortars with incorporation of microcapsules B.

\subsection{Flexural and Compressive Behavior}

The flexural and compressive behavior was determined based in the standard EN 1015-11. The specimens used for the flexural test were prismatic. The flexural tests were performed with load control at a speed of $10 \mathrm{~N} \mathrm{~s}^{-1}$. Compressive tests were realized through the application of a load on the specimen with resource to a metallic piece, rigid enough to make the vertical load uniform. The specimens used for the test were the half parts resulting from the flexural test. The compressive tests were performed with a load control at a speed of $50 \mathrm{~N} \mathrm{~s}^{-1}$.

According to the results (Figure 7), it was possible to observe a significant improvement in mechanical properties caused by the introduction of microcapsules A. However, the improvement of mechanical characteristics caused by the incorporation of microcapsules B is lower.

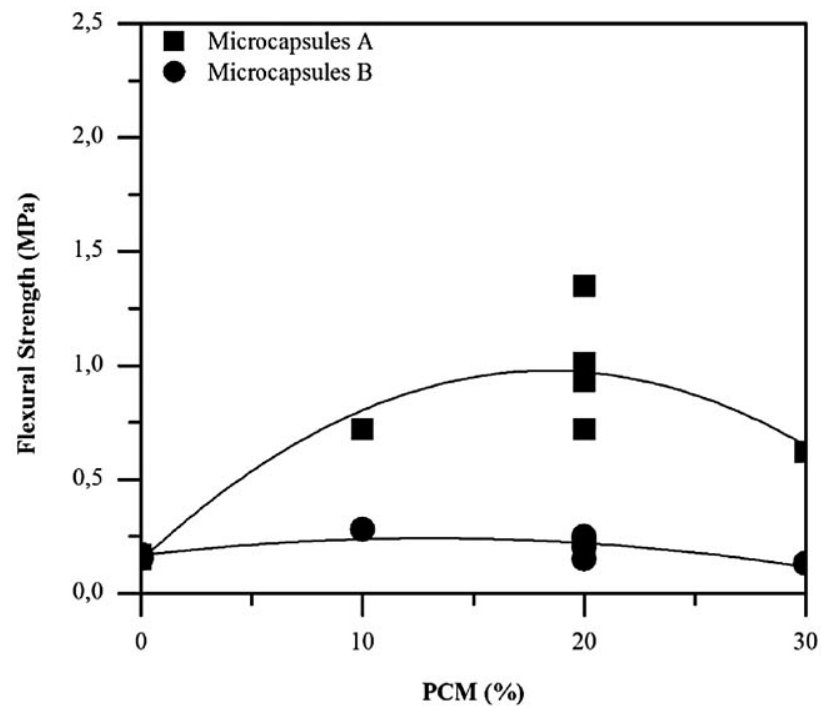

Fig. 7. Flexural and compressive behavior.
The incorporation of $10 \%$ PCM leads to an increase in the value of flexural strength of about $380 \%$ and about $600 \%$ in compressive strength for the mortars with incorporation of microcapsules A. Regarding the mortars with incorporation of microcapsules B, the increase is about $85 \%$ in flexural strength and about $130 \%$ in compressive strength. These values were obtained comparing compositions with 10\% of PCM with the composition without PCM. This increase in mechanical strengths is related to the increase of porosity caused by the introduction of higher water content and PCM presence. ${ }^{[27]}$ The increase in porosity benefits the carbonation of mortars, which was more evident in mortars with incorporation of microcapsules $\mathrm{A}$, since the water content present is higher and the surface roughness of the PCM is higher for these mortars. However, it is possible to verify a decrease in the value of compressive and flexural strength with a PCM content of $30 \%$ when compared to the $20 \%$ PCM composition. Therefore, is possible to conclude that the optimal content of PCM in terms of mechanical properties corresponds to $20 \%$. Nonetheless, the value obtained for a PCM content of $30 \%$ is slightly higher or identical than the value presented by the mortar without PCM, which allows for the conclusion of the beneficial effect caused by the incorporation of PCM in mortars.

\section{Conclusions}

Based on these results, it can be concluded that the use of PCM microcapsules in lime-gypsum mortars can be seen as a viable solution for applications in the construction industry. It is possible to achieve a viable compromise between their strength and shrinkage. However, it was also verified that the use of different PCMs microcapsules provides different characteristics in the different mortars, which is related to the type of polymer used for the construction of the wall of the microcapsules and also to their size.

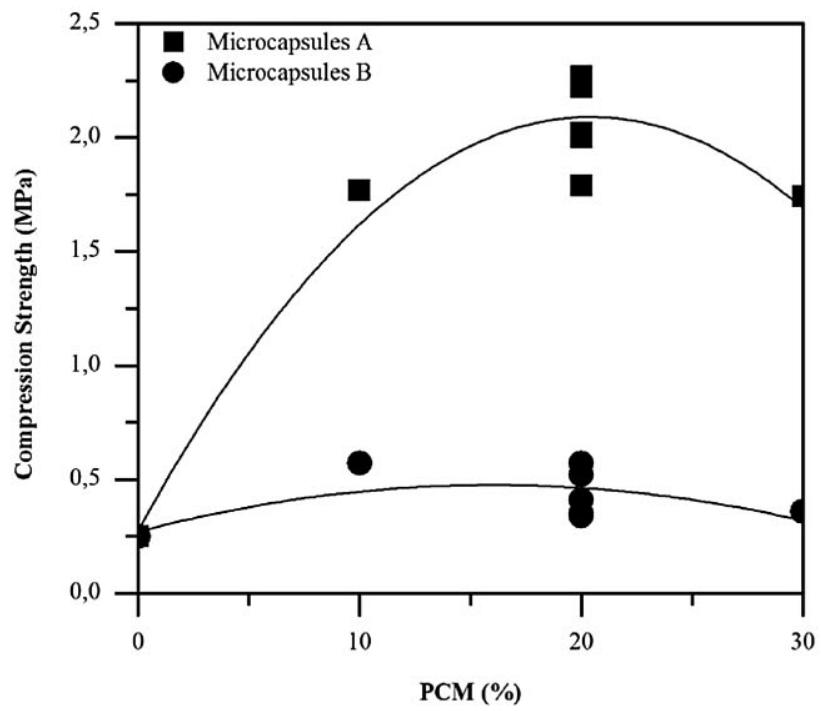


The combined use of polyamide fibers and gypsum is a good solution to solve problems related to increasing of shrinkage caused by the incorporation of polymeric microcapsules. It was also observed that the use of microcapsules B provides values of shrinkage lower than those observed in mortars with microcapsules A due to lower water content of the mortars.

It was even possible to verify the existence of a clear rise of the water necessary to incorporate into the mortar with the increase of PCM percentage, with the aim of obtaining the suitable workability.

The compressive and flexural strengths measured in each performed test indicated a better performance for a PCM microcapsules content between 15 and $20 \%$. This can be justified by the necessity of a greater amount of water in mortar with addition of $30 \%$ of PCM, causing a higher porosity, not compensated by the carbonation of mortars. It was also observed that the mortar with microcapsules A presents improved mechanical behavior compared to the mortars with microcapsules $\mathrm{B}$, which can be explained by the incorporation of a larger amount of water, which provide a greater porosity, facilitating the carbonation of the mortars. This behavior is also due to the lower roughness of the microcapsules $\mathrm{B}$.

Received: July 23, 2013

Final Version: October 16, 2013

Published online: November 14, 2013

[1] M. Diamanti, M. Ormellese, M. Pedeferri, Cement Concrete Res. 2008, 38, 1349.

[2] M. Félix, J. Aguiar, in Proc. of the 6th Asian Symp. on Polymers in Concrete, 2009, 77.

[3] N. Silva, J. Aguiar, L. Bragan a, T. Freire, I. Cardoso, Mater. Sci. Forum. 2008, 587-588, 913.

[4] Y. Zhang, G. Zhou, K. Lin, K. Zhang, H. Di, Build Environ. 2007, 42, 2197.

[5] B. Zalba, J. Marín, L. Cabeza, H. Mehling, Appl. Therm. Eng. 2003, 23, 251.

[6] E. Halawa, F. Bruno, W. Saman, Energy Convers. Manage. 2005, 46, 2592.

[7] Z. Liu, C. Ma, Energy Convers. Manage. 2002, 43, 2521.

[8] L. Cabeza, A. Castell, C. Barreneche, A. Gracia, A. Fernández, Renew. Sustain. Energy Rev. 2011, 15, 1675.
[9] V. Tyagi, S. Kaushik, S. Tyagi, T. Akiyama, Renew. Sustain. Energy Rev. 2011, 15, 1373.

[10] A. Sharma, V. Tyagi, C. Chen, D. Buddhi, Renew. Sustain. Energy Rev. 2009, 13, 318.

[11] A. Khudhair, M. Farid, Energy Convers. Manage. 2004, 45, 263.

[12] J. Li, P. Xue, H. He, W. Ding, J. Han. Energy Build. 2009, 41, 871.

[13] V. Hernández, D. Morillón, R. Best, J. Fernández, R. Almanza, N. Chargoy, Appl. Therm. Eng. 2006, 26, 2464.

[14] A. Athienitis, C. Liu, D. Hawes, D. Banu, D. Feldman, Build Environ. 1997, 32, 405.

[15] L. Shilei, Z. Neng, F. Guohui, Energy Build. 2006, 38, 18.

[16] K. Darkwa, P. O'Callaghan, D. Tetlow, Appl. Energy. 2006, 83, 425.

[17] P. Schossig, H. Henning, S. Gschwander, T. Haussmann, Sol. Energy Mater. Sol. Cells. 2005, 89, 297.

[18] M. Ahmad, A. Bontemps, H. Sallée, D. Quenard, Energy Build. 2006, 38, 673.

[19] K. Lin, Y. Zhang, X. Xu, H. Di, R. Yang, P. Qin, Energy Build. 2005, 37, 215.

[20] A. Entrop, H. Brouwers, A. Reinders, Solar Energy. 2011, $85,1007$.

[21] X. Jin, X. Zhang, Appl. Therm. Eng. 2011, 31, 1576.

[22] M. Koschenz, B. Lehmann, Energy Build. 2004, 36, 567.

[23] A. Pasupathy, L. Athanasius, R. Velraj, R. Seeniraj, Appl. Therm. Eng. 2008, 28, 556.

[24] S. Lucas, V. Ferreira, J. Aguiar, J. Labrincha, Mortars Containing Phase Change Material Microcapsules, their Preparation Process and Use, in International Patent no. WO 2011/0714022009, University of Aveiro, Portugal, 2009.

[25] European Committee for Standardization (CEN), EN 1015-11: 1999. Methods of test for mortar for masonry Part 11: Determination of flexural and compressive strength of hardened mortar. 1999.

[26] European Committee for Standardization (CEN), EN 1015-3:2004. Methods of test for mortar for masonry - Part 3: Determination of consistence of fresh mortar (by flow table). 2004.

[27] S. Lucas, V. Ferreira, J. Aguiar, in Proc. of the Conf. Sustainable Buildings: Towards 0-Impact Buildings and Environments. 2010. 